\title{
Diet Health Education Effect on Elderly Behavior with Hypertension
}

\author{
Suratun Haryono, Paula Krisanty*, Santa Manurung \\ ${ }^{1}$ Nurse Department, Health Polytechnic Ministry of Health, Jakarta III \\ J1. Arteri Jorr Jatiwarna Pondok Melati Bekasi Indonesia \\ ${ }^{*}$ Corresponding author's email: pkrisanty [AT] yahoo.com
}

\begin{abstract}
Hypertension is defined as a persistent blood pressure where the systolic pressure is above $140 \mathrm{mmHg}$ and the diastolic pressure is above $90 \mathrm{mmHg}$. Empowering patients by providing ongoing care services can create ongoing communication, building relationships between clients and service providers so that they will increase patients' confidence in overcoming problems. The visit of hypertensive patients has increased every month, health education about hypertension diet is generally carried out when the patient is diagnosed with hypertension and does not regularly monitor the implementation of the diet. The purpose of this study was to determine the difference in the effect of the approach to sustainable nursing services through health education about diet to changes in blood pressure of hypertensive patients. The research method uses a quasi-experimental design pre-post test with the control group. The study population was 108 respondents, the sampling technique used purposive sampling and obtained a sample of 33 respondents for each intervention and control group. Patient characteristics data were taken using a questionnaire, while blood pressure data was carried out by blood pressure examination. Data analysis used univariate, bivariate analysis with paired t-test statistical test. The results showed that there was a significant influence on diet health education on changes in elderly behaviour.
\end{abstract}

Keywords- Health education, Diet, behaviour, Hypertension

\section{INTRODUCTION}

Hypertension is defined as a persistent blood pressure where the systolic pressure is above $140 \mathrm{mmHg}$ and the diastolic pressure is above $90 \mathrm{mmHg}$ [1]. This disease is categorized as the silent disease because the patient does not know he has hypertension before checking his blood pressure. Hypertension that occurs for a long time and continuously can trigger a stroke, heart attack, heart failure and is a major cause of chronic kidney failure [2].

According to the World Health Organization, one billion people in the world suffer from hypertension, two-thirds of whom are in developing countries with low and medium income. The prevalence of hypertension will continue to increase sharply, predicted in 2025, around 29 per cent of adults worldwide suffer from hypertension. The prevalence of hypertension in Indonesia is obtained by measuring at> 18 years of age by 25.8 per cent and will be higher in the elderly. Therefore it is very important to check blood pressure from a young age and if found hypertension should be checked regularly and blood pressure is controlled to the recommended level by improving bad living habits and treatment [3].

Foods that are eaten directly or indirectly affect the stability of blood pressure. The content of nutrients such as fat and sodium are closely related to the appearance of hypertension. Regular diet management can normalize hypertension, namely by reducing food with high salt, fatty foods, consuming high-fibre foods and doing sports activities [4].

Data on visits of hypertensive patients in Primary Health Service has increased every month. The implementation of health education about hypertension diet in the Primary Health Service was carried out at the beginning of the patient diagnosed with hypertension and did not carry out continuous monitoring, so it was not known whether the patient carried out the diet according to the program. Related to this the researcher conducted a study entitled "The Effect of Health Education on Diets on Changing Behavior of Hypertensive Patients". The purpose of this study was to determine the difference in the effect of the approach to sustainable nursing services through health education about diet to changes in blood pressure of hypertensive patients.

\section{METHODS}

This study uses a quasi experimental design pre-post test with control group aims to determine differences in the effect of health education on hypertension diet on changes in the behavior of hypertensive patients. The population in this study were hypertensive patients as many as 108 respondents. The sampling technique uses purposive sampling. The number of samples in this study were 33 respondents in the intervention group and 33 respondents in the control group. 
The inclusion criteria determined were 1) stage 1 and 2 hypertensive patients, outpatients, able to read and write, could speak clearly, agreed to be included as research samples. The exclusion criteria determined were hypertensive patients with complications, and patients who resigned as respondents at the time of the study. The study was conducted in March to December 2016. The research was carried out in flats. Data collection tools for patient characteristics using a questionnaire, while blood pressure data by checking. Data analysis included univariate and bivariate analysis using paired t-test

\section{RESULT}

The results of the univariate analysis are shown. shows that the average age of the intervention group respondents was 61 years old, the sex of most women, the majority of them were high school education, and worked as housewives. Respondents in the control group were on average 60 years old, the sex of most women, most of them were high school educated and did not work.

The results of the bivariate analysis of the influence of health education on changes in behavior of hypertensive patients, showed that there was an increase in knowledge scores in the treatment group respondents with an increase in score 4.09, an increase in attitude scores in the treatment group respondents with an increase in score of 5.12, an increase in the action score of the respondents treatment group with an increase in score of 34.56 . So it can be concluded that there is a significant effect of health education on hypertension diet on increasing scores of knowledge, attitudes and actions of hypertensive patients with $\mathrm{p}=0,000$.

\section{DISCUSSION}

The results of the univariate analysis showed that the average treatment group respondents were 61 years of age, while the average control group respondents were 60 years old. The results of this study are in line with the results stated that the majority of respondents were 60-74 years old, both the control group and the treatment group [5]. Hypertension is closely related to age, the older a person, the greater the risk of developing hypertension over 40 years of age has a risk of developing hypertension [6]. Blood pressure increases due to natural changes in the heart and reduced elasticity of the arteries, so the incidence of hypertension is higher in old age. Increased blood pressure is also influenced by several risk factors including age, gender, family history, obesity, high salt levels, and life habits such as smoking and alcoholic beverages. For those who have these risk factors should be more vigilant and earlier in making preventive efforts, the simplest example is routine control of blood pressure more than once, and trying to avoid precipitating factors of hypertension [7].

The results of the univariate analysis showed that most of the respondents were female, both the treatment group and the control group. The results of this study support the results states that most respondents are female [8]. Likewise, the results showed that the majority of respondents were female in both the treatment and control groups [5]. Other research tates that hypertension is more experienced by women than men because there is an estrogen hormone in women [8]. The results of Primary Health Research in 2013 stated that the prevalence of hypertension in Indonesia women tended to be higher than that of men [3].

The results of univariate analysis showed that most respondents had high school education, both in the treatment group and in the control group. The results of this study are different study which states that most respondents have primary school education [8]. Likewise, the results stated that most respondents had junior high school education, both treatment groups and control groups [5]. The differences in the results of this study are likely due to differences in research sites, researchers conducted research in the Urban, while others in rural area [5,8]. Primary Health Research states that the prevalence of hypertension tends to be higher in the lower education group due to ignorance of good diet [3].

The results of the univariate analysis showed that most of the respondents in the treatment group worked as housewives, while the majority of the control group respondents did not work. The results of this study are in line with the research stated that most respondents did not work, both in the treatment group and in the control group [5]. But different from the results states that most respondents work self-employed in the treatment group, whereas in the control group most of the respondents are housewives [8].

Women who are not working or housewives have a higher risk of hypertension compared to women who work, this is probably due to the lack of activities carried out by housewives where most just stay at home with routines that make suntu, different from mothers who work instead more activities and time to do sports. In addition, usually mothers who work more actively than mothers who do not work or just as housewives. Individuals with low activity are at risk of developing hypertension $30-50 \%$ of active individuals [9].

The results of the analysis of the influence of health education on changes in knowledge of elderly hypertension showed that there was an increase in knowledge scores on the respondents in the intervention group with an increase of 
4.09 with $\mathrm{p}=0.000$, so it can be concluded that there is a significant effect of health education interventions on diet on increasing respondents' knowledge scores about hypertension diet. The results of this study support the results that states that there is an effect of low-salt diet health education on changes in knowledge of hypertensive patients, with $p=0.001$ [10]. The results of this study are in line with the other research that states there is an effect of health education on knowledge with a value of $\mathrm{p}=<0.05$ [11]. According to other research states that there is an influence of health education about hypertension diet on increasing knowledge of respondents with $p=0.015$, but in the control group there was no significant effect with $\mathrm{p}=0.839$ [5].

Knowledge is the result of sensing someone against an object through their senses. By itself at the time of sensing to produce knowledge is very much influenced by the intensity of attention and perception of the object. Most of a person's knowledge is obtained through the senses of hearing and sight. A person's knowledge of objects has different intensity or level. Knowledge is a domain that is very important for the formation of one's actions [12]. Increased knowledge is influenced by factors of health workers who have experience in providing good information in explaining in a simple but easily understood by patients and using adequate media considering that most hypertensive patients are in the elderly.

Health education about hypertension diet in this study was carried out individually using the lecture and question and answer method, with flip-chart learning media, leaflet, hypertension diet guidebook containing hypertension, how to choose and compile a hypertension diet menu and how to process food for hypertensive patients, the results are quite effective proven to increase knowledge, change attitudes and positive actions in hypertensive patients. The results of the analysis of the influence of health education on changes in attitudes of hypertensive patients, showed that an increase in attitude scores in the treatment group respondents with a magnitude increase score of 5.121 with $p=0.000$ so that it can be concluded that there is a significant effect of health education interventions on diet hypertension on changes in positive attitudes of respondents. Whereas in the control group there was no significant effect with $\mathrm{p}=0.730$.

The results of this study are in line with the results [11] study that there is an effect of health education on changes in positive attitudes with $\mathrm{p}=<0.005$. Likewise, the results of the study according [10] stated that there was a significant relationship of health education to the behavior of low-salt diets in hypertensive patients with $\mathrm{p}=0,000$. However, the results of this study are different [5] stated that there were no differences in respondents' adherence before and after receiving health education about hypertension diets in both the treatment and control groups with $\mathrm{p}=>0.05$.

Attitude is a closed response from someone to a particular stimulus that has involved the opinion and emotion factors concerned. Attitude is a syndrome in response to a stimulus, so that attitude involves the mind, feelings, attention and other psychiatric symptoms [12]. Health education is a process of changing one's attitudes and behavior that is dynamic, change is not only influenced by the transferring of material from one person to another, but changes can also occur due to awareness in individuals, groups and communities [13].

Many factors that influence the determination of attitude as a whole, such as knowledge, thinking, beliefs and emotions, all play an important role [12]. Whereas to realize the attitude of being an act becomes evident, a supporting factor or a possible condition is needed, including facilities. Other factors that influence attitude formation include personal experience, cultural influences, mass media, educational institutions, and other institutions, as well as emotional influences [14]. One of the efforts to change the patient's attitude towards the treatment program by conducting health education. His knowledge is expected to be a starting point for changes in patient attitudes and lifestyles, which in turn will change their behavior towards the treatment program they live in [15].

The results of the analysis of the effect of health education interventions on changes in patient actions showed that there was an increase in action scores on the treatment group respondents with an increase in score of 34.56 with $\mathrm{p}=$ 0.000 , it can be concluded that there is a significant effect of health education on hypertension diet on increasing the positive actions of diet patients hypertension. Whereas in the control group there was no significant effect of health education on diet on changes in the actions of respondents with $p=0.239$. This happens because of the limited types of food available so that the positive action of hypertension diet is difficult. Information from patients that the diet of hypertensive patients is the same as family members who do not suffer from hypertension such as coconut milk and cooking using more than 1 teaspoon of salt so that the food feels salty.

The results of this study support the results [8] study which states that there is a significant influence of hypertension dietary behavior on patient adherence in the intervention group with $p=0.003$, whereas in the control group there was no significant effect with $p=0.317$ [11]. stated that there were changes in the actions of hypertensive patients before and after being given health education with a value of $p=<0.05$. stated that there was a significant relationship of health education about low salt diets to positive action changes in hypertensive patients with $\mathrm{p}=0.001$ [10]. Health education is a process of changing the attitudes and behavior of a person or individual that is dynamic, change is not only influenced by the transferring of material from one person to another, but change can also occur because of awareness in individuals, groups and communities [13].

The effect of health education on hypertension diet on changes in the actions of hypertensive patients takes a long time. To find out the changes in the patient's actions towards the hypertension diet, the researcher conducted observations 
and interviews at home visits. Before intervention most hypertensive patients consume fatty foods, bersantan, eat preserved foods, use more than 1 teaspoon of salt, rarely eat vegetables and fruit. But after being given a health education intervention about hypertension diet, many patients experienced changes in their actions by dieting according to the diet guidelines given.

\section{CONCLUSION}

The results of this study indicate that there is a significant effect of health education interventions on hypertension diet on changes in knowledge, attitudes and actions of hypertensive patients between the treatment group and the control group.

\section{ACKNOWLEDGEMENT}

This research has granted ethical clearance from Ethic Committee Health Polytechnic Jakarta 2 no. LB.02.01/KE/L/168/2016.

\section{REFERENCES}

[1] Udjianti, J. Nursing Cardiovascular, Jakarta: EGC, 2010.

[2] Purnomo, H. Prevention and Treatment of the Most Deadly Diseases. Buana Library: Yogyakarta, 2009.

[3] Health Research and Development Agency Ministry of Health Republic of Indonesia. Basic Health Research, Jakarta: CV Kiat Nasa, 2013.

[4] Julianti, D. Hypertension Free with Juice Therapy, Jakarta: Puspa Swara, 2005.

[5] Saputri, Y.I. The Effect of Health Education on the Knowledge and Compliance of Diet Hypertension in the Elderly in Wironanggan Village, Gatak Sukoharjo District, UMS.ac.id/38802/22. Surakarta: FIK UMS, 2014.

[6] Sugiharto. Grade II hypertension risk factors in the community. Thesis, Semarang: Diponegoro University, 2007.

[7] Baradiro. The client of Cardiovascular Disorders, Seri Askep, Jakarta: EGC, 2008.

[8] Rosiana, A. The Effect of Hypertension Diet Behavior Assistance on Diet Compliance in Hypertension Patients in Sanggrahan Village. Skripsi. Surakarta: STIKES Kusuma Husada, 2014.

[9] Warren. Factors Related to Hypertension in Patients Treating at the Adult Polklinik Bangkinang Health Center. http// www.scribd.com, 2008.

[10] Umah, K. Effect of Health Education on the behaviour of low-salt diets in hypertensive patients: https://Ippmunigresblog.files.wordpress.com/2013/06/jurnal-zulfa.pdf, 2012.

[11] Muthe. B.T. The effect of health education on hypertension on the behaviour of hypertensive patients in the season health centre in South Sipora Subdistrict Mentawai Islands District: http://repository.unand.ac.id/1836, 2010.

[12] Notoatmojo.S. Health promotion, Theory and Application, Jakarta: Rineka, 2007.

[13] Mubarak. Health Promotion: An Introduction to teaching and learning in education. Yogyakarta: Urahara Ilmu, 2007.

[14] Azwar. Human Attitude and Measurement, Jakarta: Rineka Cipta, 2007.

[15] Siregar, C. Clinical Pharmacy Theory and Application, Jakarta: EGC, 2006. 